\title{
Editorial
}

\section{Sustainable rural retention of health workforce in Bangladesh - Is a dream or reality?} Latif SA ${ }^{1}$, Habib A ${ }^{2}$, Alam $\mathrm{MR}^{3}$

Rural retention of health workforce is a global challenge. Country like Bangladesh is facing this challenge as an acute crisis. Usually sub district areas are included as rural areas e.g. upazila health complex $\&$ union health center.

The scenario of working health manpower in sub district level is not uniform in relation to doctors and paramedics. Rural retention problem is well marked with doctors ${ }^{1}$ not significantly with other workers. Frequently print and electronic media covers the existing scenario of upazila health complex in different issues including deficiency and absenteeism of health workforces. Shortage ${ }^{1}$ and irregular recruitment of health workforce are boosting these challenges. Different initiatives were taken by the competent authority to ensure rural retention of health workforces but little success is achieved.

Mal distributions and shortage ${ }^{1,2}$ of doctors is the common scenario in our perspective. Thick populations of doctor are common in tertiary and secondary hospitals. ${ }^{1,2}$

So far it is known modest scientific works were carried out especially by directly involving doctors to find out the acceptable elucidation of this challenge.

Different types of health workforce e.g. doctor, nurse, midwife, medical assistant, medical technologist are serving in the sub district levels. Only doctors are class-I officer and much discussions and observations are persistently existing with the doctor only.

Scenario with non-HRH rural retention - All most all the times culpability is given to the doctors only regarding absenteeism in the rural remote areas; but seldom absenteeism report is seen with other cadres' class-I official. Picture of non-HRH class-I officials are necessary for a comparative assessment to find the way out; for the reason that public interest is also in part affected by the other cadre personnel.

1. *Professor Dr Shah Abdul Latif, OSD at DGHS, attached to Professor of Physiology, Dhaka Medical College, Dhaka. E-mail: shah.latif@yahoo.co.in

2. Dr Md Ahsan Habib, Assistant Professor, Department of Neurology, BSMMU. E-mail: ahsan.neurology@yahoo.com

3. Dr Md Razibul Alam, Assistant Professor, Department of Gastroenterology, BSMMU.

E-mail: razibulalam73@gmail.com

*For correspondence
Why doctors are unwilling to reside in rural remote areas? Little is known concerning the reasons behind the rural retention failure by means of scientific study by directly involving doctors posted in rural areas. Postulations may be: (a) Unwanted place of posting (b) Poor working and residing environment, for example; there is inadequate investigation and infrastructure facilities to manage a patient by a specialist doctor in the sub-district level though there are sanctioned specialist posts in the upazila health complex. (c) Administrative reasons, HRH [human resources for health] management in crossroad (d) Inadequate job satisfaction (e) No carrier planning for the doctor yet adopted by the competent authority (f) Mind set of doctor, for example; apart from urban originated medical student, a medical student who got chance from remote rural area is staying in an urban area for studying MBBS course for a minimum period of six years. His/her mind set logically became urbanized (g) Concept post graduate degree holder doctor i.e. higher medical education seeking (h) Isolation from nearest, dearest $\&$ colleagues $^{1}$ (i) Sudden change of life style (j) Other factors.

Possible remedy - World health organization conducted a series of consultative meeting to find out the ways of retention of health workforces in remote rural areas. Policy formulation $\&$ its implementation for rural retention of doctor should be in our country's socio economic perspective basis.

Safe working place and incentive: It is confidently believed that a safe working environment is a precondition to ensure rural retention. ${ }^{1,3} \mathrm{~A}$ rewarding incentive for health worker ${ }^{1}$, 2,3 for staying in remote rural area may be declared and call for inviting application from interested individual may be a trial by our ministry of health and family welfare.

Internship model: Alternatively in a model of 2 (two) years internship; compulsive one (1) year internship in remote rural area may show evidence of a good result; but this should be practiced on the basis of choice of a doctor (like 1st, 2nd, 3 rd choice of name of remote rural place, may be his/her own upazila or union).

G2YOU - Go to your own union - concept: A doctor may be asked to serve at his/her own union or upazila level for a period of 2 years. After successful completion of 2 years services in his/her own remote rural area; a doctor must be posted at his desired place of posting. In that case regular recruitment must be ensured. Choice of incumbent may be taken as 1st, 2nd, 3rd name of place of posting; for the reason that getting a desire "training post in tertiary hospital" by a doctor is now a dream and competition. 
Rural Health Authority (RHA) model: May be a thought by the government. RHA may recruit a doctor from its locality for a minimum period of two (2) years. This two (2) years service certificate shall be used for getting chance in higher studies or higher administrative posts.

Autonomous institutes: Full autonomy of medical colleges, institutes, secondary and tertiary hospitals may be another brainstorm to augment rural retention of health workforces by indirect approach. May be it is a highly ambitious agenda for the government.

Rural quota notion: Input of 1st year MBBS students from remote rural quota basis may be a trial for rural retention. In this case a student supposed to pass SSC \& HSC from a remote rural school and college.

Lesson learned idea: On the basis of lessons learned from earlier programs our ministry of health and family welfare of Bangladesh may revisit the health, population and nutrition sector development program (HPNSDP) for taking effective measures for ensuring rural retention of health workforces. ${ }^{2}$
In conclusion, rural retention of health workforces (especially doctor) is a great challenge for each government of the developing countries. Rural retention in Bangladesh should be overcome by means of series of evidence based country case studies by involving policy makers, health workforces, patients (common peoples) \& other concerned.

\section{References}

1. Rajja M. Why doctors are reluctant to work in rural areas? Available from: http://www.thefinancialexpress-bd. com/more.php?news_id=140826\&date=2012-08-24

2. WHO Bangladesh; Global health workforce alliance. Available from: http://www.who.int/workforcealliance/ countries/bgd/en/index.html

3. WHO global recommendations for the retention of health workers. Available from: http://www.who.int/ hrh/migration/retention/en/ 